9. Wuchter C, Ratei R, Spahn G, Schoch C, Harbott J, Schnittger S, et al. Impact of CD133 (AC133) and CD90 expression analysis for acute leukemia immunophenotyping. Haematologica. 2001;86:154-61.

10. Yin AH, Miraglia S, Zanjani ED, Almeida-Porada G, Ogawa M, Leary AG, et al. AC133, a novel marker for human hematopoietic stem and progenitor cells. Blood. 1997;90:5002-12.
11. Kloss CC, Condomines M, Cartellieri M, Bachmann M, Sadelain M. Combinatorial antigen recognition with balanced signaling promotes selective tumor eradication by engineered T cells. Nat Biotechnol. 2013;31:71-75.

12. Liu H, Westergard TD, Cashen A, Piwnica-Worms DR, Kunkle L, Vij R, et al. Proteasome inhibitors evoke latent tumor suppression programs in pro-B MLL leukemias through MLL-AF4. Cancer Cell. 2014;25:530-42.

Leukemia (2018) 32:2016-2020

https://doi.org/10.1038/s41375-018-0220-z

Stem cell biology

\title{
Identification of immune-activated hematopoietic stem cells
}

\author{
Nir Bujanover ${ }^{1,2} \cdot$ Oron Goldstein $^{1,2,3} \cdot$ Yariv Greenshpan ${ }^{1} \cdot$ Hodaya Turgeman $^{1} \cdot$ Amit Klainberger $^{1,2} \cdot$ \\ Ye'ela Scharff ${ }^{1,2} \cdot$ Roi Gazit $\mathbb{D}^{1,2,3}$
}

Received: 14 January 2018 / Revised: 24 June 2018 / Accepted: 29 June 2018 / Published online: 24 July 2018

(c) The Author(s) 2018. This article is published with open access

Hematopoietic stem cells (HSCs) are the source of both normal blood cells and leukemia [1]. The ability to identify and purify them using multiple surface markers, such as Lineage ${ }^{-}$ $\mathrm{cKit}^{+} \mathrm{Sca} 1^{+} \mathrm{CD} 34^{-} \mathrm{CD} 48^{-} \mathrm{CD} 150^{+}$, facilitates the study of molecular mechanisms and dynamics of hematopoiesis [2, 3]. However, the identification of HSCs under immunestimulation conditions poses a major challenge due to considerable changes in their pivotal markers, including Scal and CD150, following stimulation [4-10]. Therefore, we employ the $F g d 5^{\text {mCherry }}$ reporter mouse to improve identification of activated HSCs. $F g d 5$ is specifically expressed in HSCs of all hematopoietic cells, and the knocked-in Fgd5 ${ }^{\text {mCherry }}$ reporter mouse was reported to specifically label HSCs under naivestate [11]. Here, we utilize $F g d 5^{\text {mCherry }}$ to demonstrate the specific labeling of long-term multipotent cells under immune-stimulatory conditions, achieving better

Electronic supplementary material The online version of this article (https://doi.org/10.1038/s41375-018-0220-z) contains supplementary material, which is available to authorized users.

Roi Gazit

gazitroi@bgu.ac.il

1 The Shraga Segal Department for Microbiology, Immunology and Genetics, Faculty of Health Sciences, Ben-Gurion University of the Negev, POB 84105 Beer-Sheva, Israel

2 National Institute for Biotechnology in the Negev, Ben-Gurion University of the Negev, Beer-Sheva, Israel

3 Present address: Center for Regenerative Medicine and Stem Cells, Ben-Gurion University of the Negev, Beer-Sheva, Israel identification of activated-HSCs. RNA-Seq. data of purified Lineage ${ }^{-} \mathrm{CKit}^{+} \mathrm{Sca}^{+} \mathrm{CD} 150^{+} \mathrm{Fgd} 5^{\mathrm{mCherry}+} \quad\left(\mathrm{LSK} 150^{+} \mathrm{mC}^{+}\right)$ reveal molecular-changes in HSCs upon stress. We further identify CD317 (Bst2) and CD69 as new activation-markers of HSCs, demonstrating the response to stimulation at single-cell FACS resolution. This study thus presents the first mouse reporter for HSCs during immune stimulation, and highlights novel markers to monitor HSCs under stress conditions.

Using polyinosinic-polycytidylic acid (pIC), we stimulated a type-I interferon response in $F g d 5^{\text {mCherry }}$ mice. We found that acute stimulation increased the expression of both Sca1 and CD150 (Fig. 1a, Supplementary Figure 1), in agreement with previous studies $[5,8,9]$. Importantly, $24 \mathrm{~h}$ post stimulation, the increase in Scal shifted almost the entire Lineage ${ }^{-} \mathrm{CKit}^{+} \mathrm{Scal}^{-}$(LK) population into the Line$\mathrm{age}^{-} \mathrm{cKit}^{+} \mathrm{Scal}^{+}$(LSK) gate (Fig. 1a, b, Supplementary Figure 1). At 48 and $72 \mathrm{~h}$ post stimulation, the expression of both Sca1 and CD150 slowly reversed (Fig. 1b, Supplementary Figure 1). It is possible that part of the LK population was lost following stimulation, while many of these cells shift into the LSK-gate, which is in agreement with previous studies [5, 9]. Mobilization of the LSK population to peripheral-blood or spleen was not significant (data not shown). Dissection of the bone-marrow LSK compartment using $\mathrm{CD} 150$ and $\mathrm{Fgd5^{ \textrm {mCherry } }}(\mathrm{mC})$ revealed that the frequency of $\mathrm{LSK} 150^{+} \mathrm{mC}^{-}$population, but not the LSK $150^{+} \mathrm{mC}^{+}$population, increased significantly (Fig. 1b top). Following an LPS stimulation, or an extended stimulation over 8 days, Scal and CD150 showed a similar increase of expression, while the frequency LSK $150^{+} \mathrm{mC}^{+}$ population was unchanged (Supplementary Figures 2-3). 
a
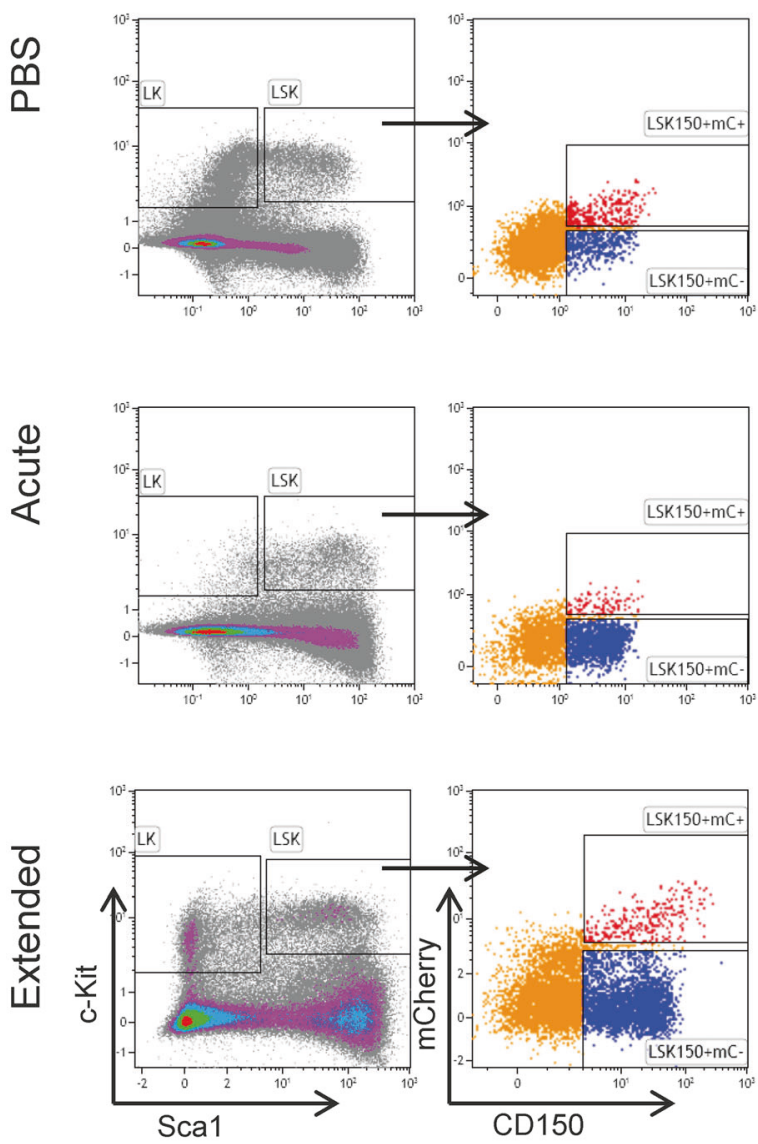

C

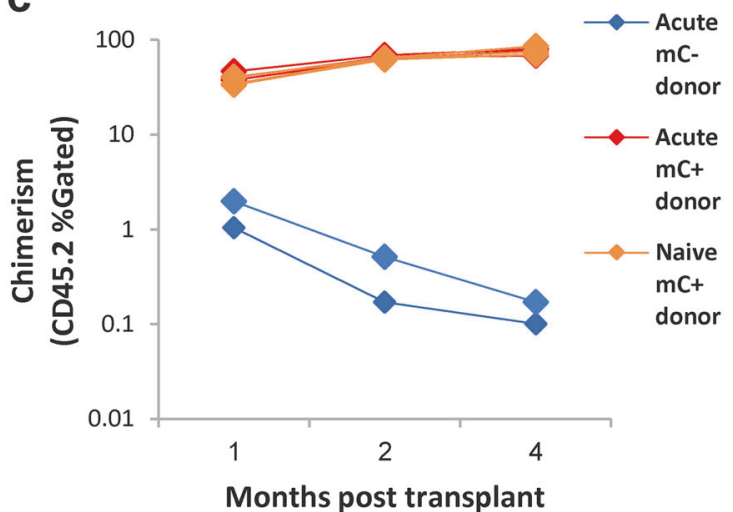

Fig. 1 Acute and extended immune stimulation provokes conventional HSC markers. a Representative FACS plots, showing the staining of the Lineage ${ }^{-} \mathrm{cKit}^{+} \mathrm{Scal}^{+}$(LSK) compartment (left panels) and its dissection by $\mathrm{CD} 150$ and the $\mathrm{Fgd} 5^{\mathrm{mCherry}}$ reporter (mC, right panels) under control conditions (top) and under acute (middle) and extended (bottom) pIC stimulation, $24 \mathrm{~h}$ post stimulation. b Quantification of the frequencies of indicated cell populations: Lineage-cKit ${ }^{+} \mathrm{Scal}^{-}$(LK),

To functionally define this $F g d 5^{\text {mCherry }}$ dissection of the LSK150 compartment, we transplanted either LSKCD $150^{+} \mathrm{mC}^{-}$or LSKCD $150^{+} \mathrm{mC}^{+}$cells together with
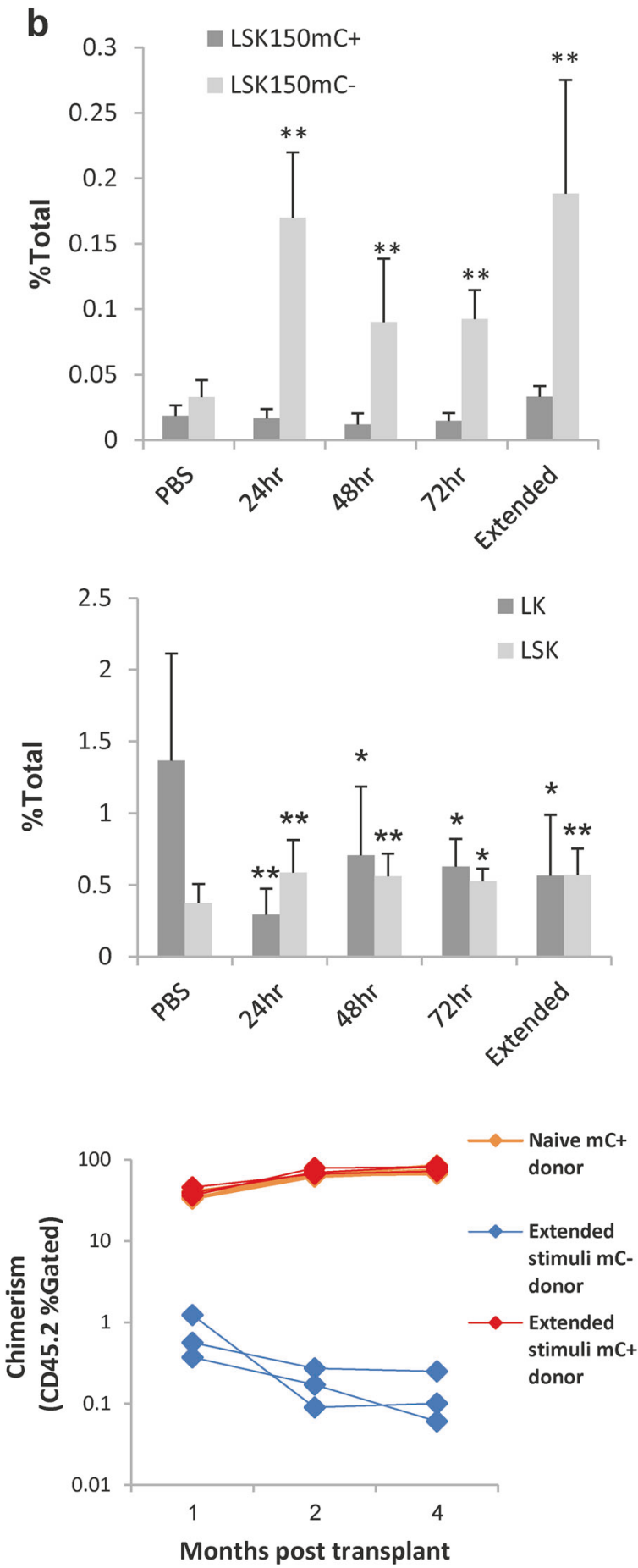

Lineage $^{-} \mathrm{cKit}^{+} \mathrm{Sca}^{+}(\mathrm{LSK}), \mathrm{LSKCD} 150^{+} \mathrm{mC}^{-}$, and LSKCD150 ${ }^{+} \mathrm{mC}^{+}$. Histograms indicate mean frequency and standard deviation from the bone-marrow mononuclear cells (\% of total). c LSKCD $150^{+} \mathrm{mC}^{+}$are functional HSCs. Chimerism (\% of gated CD45.2 cells) over time following acute or extended pIC-stimulated donors. Data are from at least five mice per histogram; $* p<0.05, * * p<0.01$

congenic CD45.1 competitors into F1 recipients (Fig. 1c). This competitive-transplant enables three-way separation for competitor $\left(45.1^{+} 45.2^{-}\right)$, host $\left(45.1^{+} 45.2^{+}\right)$, and donor $\left(45.1^{-}\right.$ 


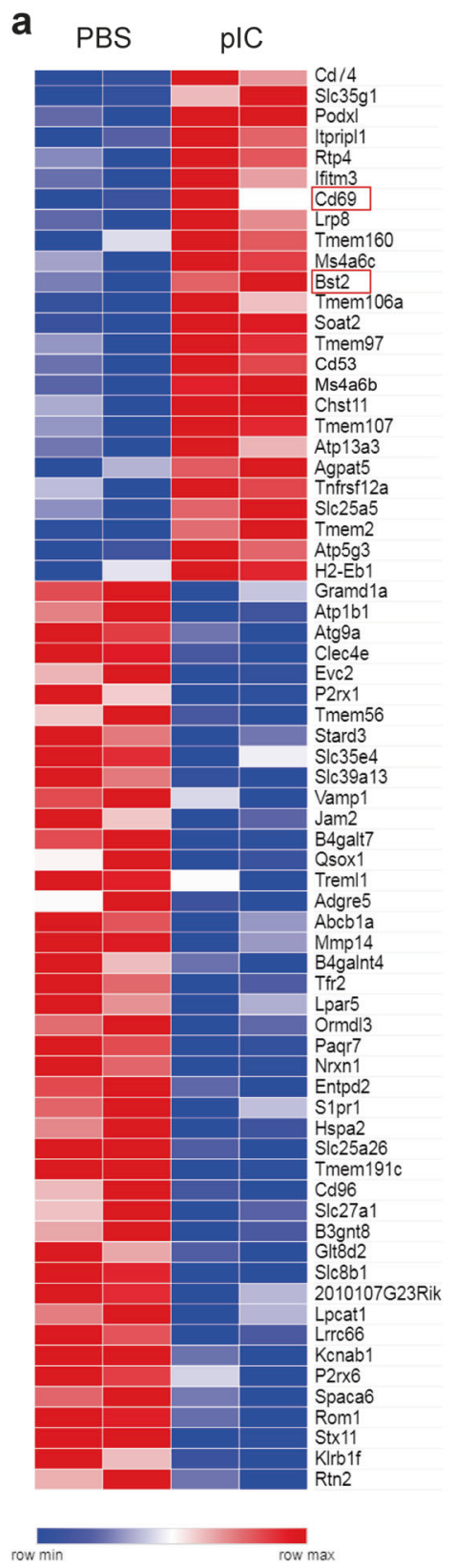

Fig. 2 Surface markers of acutely activated HSCs. a A heatmap of 75 differentially expressed (DE) surface markers (GO:0016021, of 435 DE genes) under control (PBS) conditions and $24 \mathrm{~h}$ after an acute pIC stimulation. b Representative FACS plots showing the expression of CD69 (x-axis) and CD317 (Bts2, $y$-axis) in control conditions (PBS; top panels) and $24 \mathrm{~h}$ after an acute pIC stimulation (bottom panels). Plots are shown for the Lineage-negative ( $\mathrm{Lin}^{-}$, left panels), Lineage

$45.2^{+}$), as shown in Supplementary Figure 4. Representative FACS plots (Supplementary Figures 4-7) demonstrate the analysis of test donor cells as myeloid $\mathrm{Macl}^{+} \mathrm{Gr}^{-}$and Mac1 ${ }^{+} \mathrm{Gr} 1^{+}$cells, or lymphoid CD3e ${ }^{+}$T-cells and B220 ${ }^{+}$B-cells. Invariably, the $\mathrm{LSK} 150^{+} \mathrm{mC}^{+}$cells, and not the $\mathrm{LSK} 150^{+} \mathrm{mC}$ - cells, showed a robust multipotent long-term activity from either acute-stimulated or extended-stimulated bone-marrow cells (Fig. 1c, Supplementary Figures 4-7). Therefore, we gain

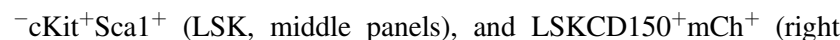
panels) populations. $\mathbf{c}$ Quantification of the frequencies of indicated populations of $\mathrm{CD} 9^{+} \mathrm{CD} 317^{+}$(green), $\mathrm{CD} 317^{+} \mathrm{CD}^{-} 9^{-}$(red), and $\mathrm{CD} 9^{+} \mathrm{CD} 317^{-}$(blue) cells. Histograms show averages and standard deviations of the control (PBS) and pIC-treated (Acute) cells; $* p<$ $0.05, * * p<0.01$

better identification of HSCs under stress conditions. The LSKCD $150^{+} \mathrm{mC}^{-}$population showed relatively little expression of EPCR, which is important for repopulationactivity, and a low frequency of quiescence (data not shown).

After phenotypically and functionally identifying HSCs under immune-stimulation conditions, we continued to generate and analyze whole-transcriptome RNA-Seq data of LSKCD $150^{+} \mathrm{mC}^{+}$cells. Figure $2 \mathrm{a}$ shows differentially 
expressed genes of surface proteins of immune-stimulated HSCs, suggesting novel candidate markers for activated HSCs. Transcriptome data and RT-qPCR validation showed a pronounced increase in type-I and type-II interferons (IFNs; 163 out of the 435 significantly differentially expressed genes), a complex cell-cycle alteration; and a small change in HSC genes (16 out of 325), except for Ly6a (Sca1) and MycN (Supplementary Figure 8-9). The induction of cellcycle progression under type-I IFN stimulation is not common, but not entirely unique to HSCs, as other immune cells, such as Th1 and NK cells, are known to proliferate upon IFN stimulation [12]. Intriguingly, the proliferation of HSCs is supported by the up-regulation of positive cell-cycle regulators for DNA synthesis, such as the origin recognition complex subunit 1 (Orcl), and a reduction in $\mathrm{Meg} 3$, which was recently shown to sustain HSC quiescence [13]. Conversely, upregulation of BTG anti-proliferation factor 3 (Btg3) and downregulation of the protein regulator of cytokinesis 1 (Prcl), are suggesting a genetic program to revert into quiescence already at the acute-activation stage, which is in agreement with previously published functional data [5].

Candidate activation-markers includes Clec2c (CD69) and the bone marrow stromal cell antigen 2 (Bst2, also known as CD317). Importantly, expression changes may be uniform across all cells or heterogeneous at single-cell resolution. The latter alternative is of interest, as the HSC population is known to be functionally heterogeneous [14]. FACS analysis revealed an increase in CD317 and CD69 after acute pIC stimulation, confirming the RNA-Seq data to the protein level (Fig. 2b, c, Supplementary Figure 10). Notably, the increase in CD317 was uniform across all HSCs and across some of the early multipotent progenitors, suggesting that all of these cells responded to the IFN stimulation. In contrast, CD69 was only increased in part of the population, suggesting that some HSCs are more responsive to the stimulation than others. The identification of surface markers for HSC activation will enable the dynamic examination of the response and may pave the way towards functional examination of sub-populations of HSCs under stress.

Our data show that during immune stimulation, the majority of the LSK $150^{+}$population is non-HSC. Progenitor cells activities during infection will require further study, especially following their shift of expression of pivotal markers. This finding possesses a warning, as even an advanced single-cell analysis would confront the challenge of accounting for non-HSCs and could yield an ambiguous "novel classification" of HSC sub-populations. Our study demonstrates that $\mathrm{Fgd} 5^{\text {mCherry }}$ reliably identifies stimulated HSCs, which retain transplantation potency following an acute stimulation; this notion is in agreement with the findings of Matatall et al. [7], who elegantly demonstrated that the reduction in HSCs and in repopulation activity was significant only after more than 2 months of $M$. avium infection.
It is yet to be determined whether HSCs play an essential physiological role in the inflammatory response, or whether they are activated as an innate response to an unknown threat. The CD317 expression pattern is providing the first direct evidence that all HSCs rapidly react to IFN, suggesting that the bone marrow niche is highly permeable in the context of immune stimulation. The observed heterogeneity in CD69 expression is in agreement with a functional heterogeneity among HSCs following infection [6], and suggests future functional assessment of HSC's sub-populations. Interestingly, a very-recent study demonstrated potential mobilization and activation of HSCs and progenitors in a human-CD69 mouse model [15], suggesting further interest in this receptor. The identification of HSC-activation markers will enable the studies to refine the dynamic analysis of HSC during stressinduced hematopoiesis, which may lead to leukemia. The ability to better control our endogenous adult stem cells provides new opportunities to avoiding premature aging and a hazardous progression to pre-malignancy.

Acknowledgements We are thankful to Uzi Hadad for FACS sorting, Shlomit Raz-Yahalom for FACS analysis, the Israel National Center for Personalized Medicine for RNA-seq, and Ron Apte for advice on immune stimulation protocols. This study was supported by grants GIF- I-1124-203.8-2013, MOST 3-12890, and BSF-2015248.

Author contributions NB: Conception and design, collection and/or assembly of data, data analysis and interpretation, manuscript writing. OG: Collection and/or assembly of data. YG: Collection and/or assembly of data. HT: Collection and/or assembly of data. AK: Collection and/or assembly of data, data analysis and interpretation. YS: Collection and/or assembly of data. RG: Conception and design, collection and/or assembly of data, data analysis and interpretation, manuscript writing.

\section{Compliance with ethical standards}

Conflict of interest The authors declare that they have no conflict of interest.

Open Access This article is licensed under a Creative Commons Attribution 4.0 International License, which permits use, sharing, adaptation, distribution and reproduction in any medium or format, as long as you give appropriate credit to the original author(s) and the source, provide a link to the Creative Commons license, and indicate if changes were made. The images or other third party material in this article are included in the article's Creative Commons license, unless indicated otherwise in a credit line to the material. If material is not included in the article's Creative Commons license and your intended use is not permitted by statutory regulation or exceeds the permitted use, you will need to obtain permission directly from the copyright holder. To view a copy of this license, visit http://creativecommons. org/licenses/by/4.0/.

\section{References}

1. Koeffler HP, Leong G. Preleukemia: one name, many meanings. Leukemia. 2017;31:534-42. 
2. Gazit R, Garrison Brian S, Rao Tata N, Shay T, Costello J, Ericson $\mathrm{J}$, et al. Transcriptome analysis identifies regulators of hematopoietic stem and progenitor cells. Stem Cell Rep. 2013;1:266-80.

3. Busch K, Klapproth K, Barile M, Flossdorf M, Holland-Letz T, Schlenner SM, et al. Fundamental properties of unperturbed haematopoiesis from stem cells in vivo. Nature. 2015;518:542-6.

4. Haas S, Hansson J, Klimmeck D, Loeffler D, Velten L, Uckelmann $\mathrm{H}$, et al. Inflammation-induced emergency Megakaryopoiesis driven by hematopoietic stem cell-like Megakaryocyte progenitors. Cell Stem Cell. 2015;17:422-34.

5. Pietras EM, Lakshminarasimhan R, Techner JM, Fong S, Flach J, Binnewies $\mathrm{M}$, et al. Re-entry into quiescence protects hematopoietic stem cells from the killing effect of chronic exposure to type I interferons. J Exp Med. 2014;211:245-62.

6. MacLean AL, Smith MA, Liepe J, Sim A, Khorshed R, Rashidi NM, et al. Single cell phenotyping reveals heterogeneity among hematopoietic stem cells following infection. Stem Cells. 2017;35:2292-304.

7. Matatall KA, Jeong M, Chen S, Sun D, Chen F, Mo Q, et al. Chronic infection depletes hematopoietic stem cells through stress-induced terminal differentiation. Cell Rep. 2016;17:258495.

8. Baldridge MT, King KY, Boles NC, Weksberg DC, Goodell MA. Quiescent haematopoietic stem cells are activated by IFN-gamma in response to chronic infection. Nature. 2010;465:793-7.
9. Essers MA, Offner S, Blanco-Bose WE, Waibler Z, Kalinke U, Duchosal MA, et al. IFNalpha activates dormant haematopoietic stem cells in vivo. Nature. 2009;458:904-8.

10. Sato T, Onai N, Yoshihara H, Arai F, Suda T, Ohteki T. Interferon regulatory factor-2 protects quiescent hematopoietic stem cells from type I interferon-dependent exhaustion. Nat Med. 2009;15:696-700.

11. Gazit R, Mandal PK, Ebina W, Ben-Zvi A, Nombela-Arrieta C, Silberstein LE, et al. Fgd5 identifies hematopoietic stem cells in the murine bone marrow. J Exp Med. 2014;211:1314-30.

12. Welsh RM, Bahl K, Marshall HD, Urban SL. Type 1 interferons and antiviral CD8 T-cell responses. PLoS Pathog. 2012;8: e1002352.

13. Qian P, He XC, Paulson A, Li Z, Tao F, Perry JM, et al. The Dlk1 ${ }^{-}$Gt12 locus preserves LT-HSC function by inhibiting the PI3KmTOR pathway to restrict mitochondrial metabolism. Cell Stem Cell. 2016;18:214-28.

14. Clapes T, Lefkopoulos S, Trompouki E. Stress and non-stress roles of inflammatory signals during HSC emergence and maintenance. Front Immunol. 2016;7:487.

15. Notario L, Alari-Pahissa E, Albentosa A, Leiva M, Sabio G, Lauzurica P. Anti-CD69 therapy induces rapid mobilization and high proliferation of HSPCs through S1P and mTOR. Leukemia 2018;32:1445-1457.

Leukemia (2018) 32:2020-2024

https://doi.org/10.1038/s41375-018-0208-8

Myelodysplastic syndrome

\title{
Clonal hematopoiesis in patients with multiple myeloma undergoing autologous stem cell transplantation
}

\author{
Sneha Chitre ${ }^{1}{ }^{1} \cdot$ Friedrich Stölzel $^{2} \cdot$ Kirsty Cuthill $^{1} \cdot$ Mathew Streetly $^{1} \cdot$ Charlotte Graham $^{1} \cdot$ Claudia Dill $^{2}$. \\ Azim Mohamedali ${ }^{1}$ - Alexander Smith ${ }^{1} \cdot$ Johannes Schetelig $^{2,3} \cdot$ Heidi Altmann ${ }^{2} \cdot$ Martin Bornhäuser $^{1,2}$. \\ Ghulam J. Mufti ${ }^{1}$
}

Received: 29 January 2018 / Revised: 9 May 2018 / Accepted: 20 June 2018 / Published online: 19 July 2018

(c) Macmillan Publishers Limited, part of Springer Nature 2018

Electronic supplementary material The online version of this article (https://doi.org/10.1038/s41375-018-0208-8) contains supplementary material, which is available to authorized users.

Sneha Chitre

sneha.s.shinde@kcl.ac.uk

1 Department of Haematological Medicine, The Rayne Institute, King's College London, London, UK

2 Department of Internal Medicine I, Dresden University of Technology, Dresden, Germany

3 Present address: Clinical Trials Unit, DKMS German Bone Marrow Donor Center, Dresden, Germany
Treatment for multiple myeloma (MM) has improved considerably over the last decade leading to markedly improved survival rates, long-term disease control, or even cure [1]. Improvement in treatment with increased survival rates render these patients at an increased risk for second primary malignancies like acute myeloid leukemia (AML)/myelodysplastic syndromes (MDS) [2]. Treatment with chemotherapy and/or radiotherapy for MM may induce clonal hematopoiesis of indeterminate potential (CHIP) or promote selection of pre-existing CHIP clones in residual hematopoietic cells. The incidence of CHIP in patients with nonHodgkin lymphoma (NHL) has been detected in up to $29 \%$ and is associated with inferior survival and a higher risk of 